\title{
DOCUMENTING A UNESCO WH SITE IN CYPRUS WITH COMPLEMENTARY TECHNIQUES
}

\author{
G. Bariami ${ }^{1}$, M. Faka ${ }^{1}$, A. Georgopoulos ${ }^{1}$, M. Ioannides ${ }^{2}$, D. Skarlatos ${ }^{3}$ \\ ${ }^{1}$ Laboratory of Photogrammetry, National Technical University of Athens, Greece \\ ${ }^{2}$ Electrical Eng. and Information Technology Dept., Cyprus University of Technology \\ ${ }^{3}$ Civil and Geomatics Engineering Dept., Cyprus University of Technology \\ gwgw_bariami@hotmail.gr, marinafaka@gmail.com,drag@central.ntua.gr, gammat@cytanet.com.cy, \\ dimitrios.skarlatos@cut.ac.cy
}

\section{CIPA, ICOMOS and WG V/2: Advances in Digital Documentation}

KEY WORDS: Cultural Heritage, Photogrammetry, TLS, Orthoimage, Rendering

\begin{abstract}
:
According to UNESCO directives, the documentation of monuments is a complex task, which both terrestrial laser scanning (TLS) and photogrammetry can decisively support. Today, these techniques are considered complementary, as they demonstrate clear advantages and disadvantages to each other, with regard to representation, texture application, data gathering, acquisition and processing time, practicality, accuracy, data density, surface reflectivity and absorption. In an effort to clarify which part should be acquired with which technique, as well as to understand whether one technique has a clear advantage over the other in some specific task of the documentation process, the Church of the Holy Cross in Pelendri, Cyprus, which is a UNESCO World Heritage monument, was selected as a test site. The deliverables are orthophotos, sections, plots and a complete and accurate 3D model of the monument. The whole documentation process has been carried out independently using an image based technique with Menci's ZScan and terrestrial laser scanning Leica's ScanStation 2, supported by high resolution digital images. Data acquisition has been carried out in parallel while the final products have been created independently by each one. It is clear that the processing phase of photogrammetry is more time consuming than the equivalent in TLS, but high quality texturing and the orthophoto production process are included within the processing, hence image based techniques present an advantage. As for their final accuracy, both techniques deliver satisfactory results within the required scale tolerances. Their individual merits are also presented, discussed and evaluated in this paper.
\end{abstract}

\section{INTRODUCTION}

One of the three UNESCO WH sites in Cyprus is the group of the ten painted Byzantine Churches in the Mount Troodos

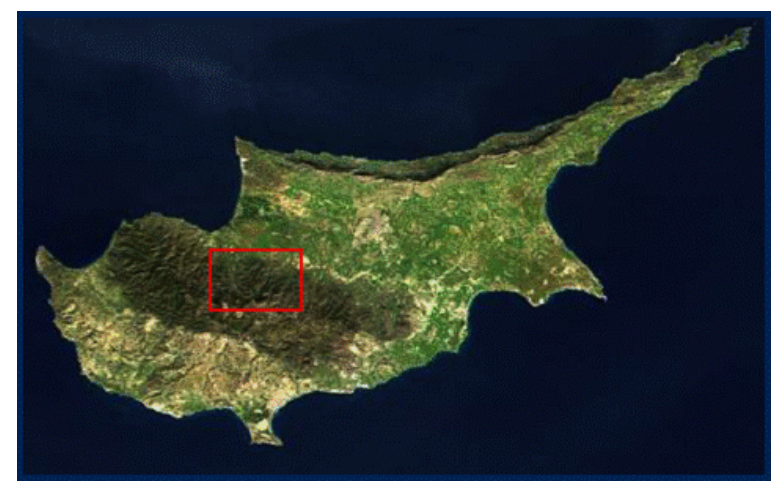

Figure 1: The WH site on Mount Troodos in Cyprus

(Figure 1). They date from the $11^{\text {th }}$ c. AD and are famous worldwide for their architecture and frescoes. The Laboratory of Photogrammetry in cooperation with HTI initially and CUT, Dept. of Electrical Eng. and Information Technology nowadays and with the help of the Church of Cyprus and the Department of Antiquities of Cyprus has undertaken an effort for their documentation and three dimensional visualization, with contemporary techniques (Sophocleous et al. 2006, Agapiou et al. 2008a and 2008b, Chrysostomou et al. 2008, Georgopoulos et al. 2009, Agapiou et al. 2010).

The geometric documentation of a monument may be defined as the action of acquiring, processing, presenting and recording the necessary data for the determination of the position and the actual existing form, shape and size of a monument in the three dimensional space at a particular given moment in time (UNESCO 1972). The geometric documentation records the present of the monuments, as this has been shaped in the course of time and is the necessary background for the studies of their past, as well as the plans for their future and e-preservation.

Technological advances in recent years have spectacularly multiplied the variety of sources for collecting metric information at such large scales. In order to fully exploit these data, special techniques should be developed. Moreover, the advancements in computer industry have enabled the three dimensional visualizations of the monuments in a virtual world. The compilation of $3 \mathrm{D}$ models of historical monuments is considerably facilitated by the use of dense point clouds, which are created by terrestrial laser scanners. Their combined use with photogrammetric procedures, such as the production of orthophotos, allows the realistic 3D representation of complex monuments such as sculptures. In this context virtual reality tours have been created for simple or more complex monuments (Georgopoulos \& Ioannidis, 2007). This ability has greatly contributed to the thorough study of the monuments, as well as to the creation of virtual visits. At the same time, the plethora of 
methods proposed by the manufacturers offers a multitude of alternatives to the potential user. The purpose of this paper is to investigate the possibilities and limitations of two different approaches to the geometric documentation of the Church of the Holy Cross in Pelendri Cyprus.

\section{DESCRIPTION OF THE SITE}

\subsection{History of the Church of the Holy Cross}

The Byzantine church of the Holy Cross is located in the village of Pelendri in the region of the Mount Troodos in Cyprus. Inside the monument the wall paintings are of such great artistic value that the church has been included on the World Heritage List of UNESCO together with 9 others of the same region. The current form of the monument is the result of many additions and alterations upon the initial construction phase. The Church of the Holy Cross is a basilica with a dome (Figure 2).

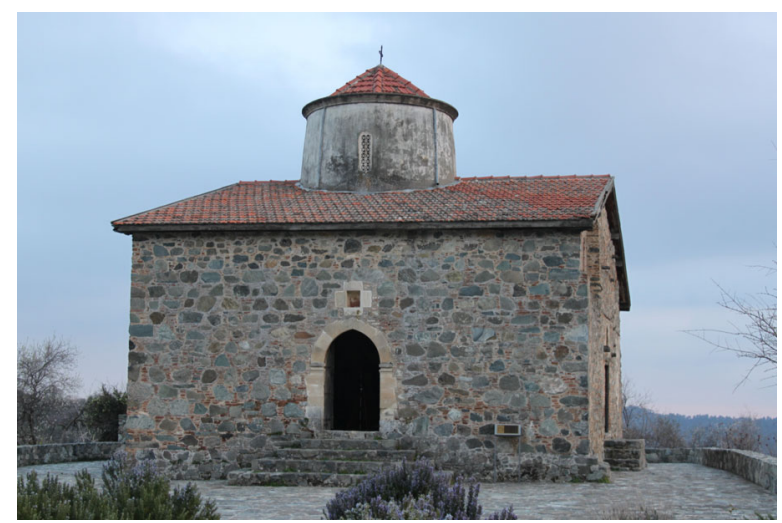

Figure 2: The Church of the Holy Cross in Pelendri

The monument appears to have been built in the 1178 A.D, according to an inscription on the apse of the sanctuary. The original church was single aisled with a dome in the centre and arched recesses in the side walls. In the early 14th century the church was destroyed by an unknown cause. During the rebuilding of the church at that time and probably in the same reconstructive project, two aisles were added one to the north and one to the south.

The existence of old wall paintings was revealed under the 14th century layer of plaster in the main apse, during maintenance works of the church in the early 70's. Following the discovery of these frescoes of the $12^{\text {th }} \mathrm{c}$. during the cleaning and maintenance of the decoration of the church by the Department of Antiquities of Cyprus, those of the second layer were detached and placed onto an additional drywall at the corresponding point of the south aisle, where they have been up to the present day. The frescoes have serious damages because of the decorative plastering in the $14^{\text {th }}$ century (Hadjichristodoulou 2005, Zarras 2010).

\section{METHODOLOGY}

For the geometric documentation and $3 \mathrm{D}$ visualization of the Church of the Holy Cross, two different approaches were employed. Firstly, the "classical" contemporary methodology involving laser scanning and high resolution digital imagery for producing the 2D imagery products, i.e. orthophotos, and for texturing of the 3D model. On the other hand the ZScan system by Menci was employed. As it will be described later, it is a purely image based hardware and software combination for producing $2 \mathrm{D}$ and $3 \mathrm{D}$ geometric documentation products.

\subsection{Description of survey network}

All data acquisition actions should be referenced to a common coordinate system, in order to enable the necessary interrelations. A survey network is essential for this purpose. Two interconnected traverses were established, one outside (E1E6) and one inside (m1-m6) the church (Figure 3) in such a way to allow measurements to all parts of the monument.

Using contemporary total stations (Topcon GPT 7003i and Leica TPS 1200) the measurements of the network resulted to an adjustment accuracy of less than $10 \mathrm{~mm}$. The survey stations were discretely marked with small paper targets.

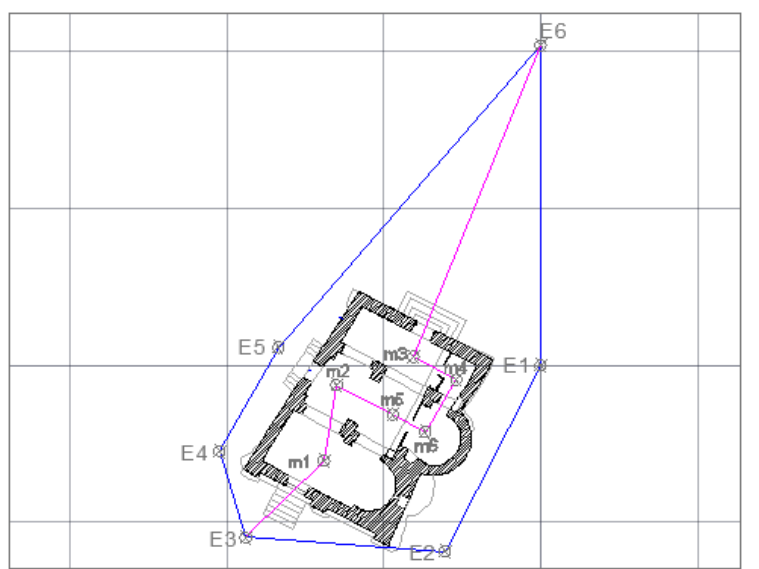

Figure 3: The network established outside and inside the Church of the Holy Cross

\subsection{Data acquisition}

3.2.1 TLS and Digital Imagery: Data acquisition was carried out using terrestrial laser scanning and classical photogrammetric methods. A Leica ScanStation 2 ToF laser scanner was used to collect the point clouds of $1 \mathrm{~cm}$ density from the outside and the inside of the church. At least three targets common to each pair of scans were positioned either on the walls or on tripods for aligning the point clouds later. A Canon EOS MIII full frame $21 \mathrm{MP}$ DSLR with a $24 \mathrm{~mm}$ and a $50 \mathrm{~mm}$ calibrated lenses was used for acquiring the digital images. Effort was made to take these images as frontal as possible, especially in the interior, in order to render the 3D model and produce the orthophotos as reliably as possible.

Either pre-marked points or detail points were used as GCP's. All GCP's and scanner targets were measured with the total stations and referred to the common coordinate system. This would help the point cloud registration and ensure maximum accuracy.

Laser scanning for the exterior and the interior of the church lasted 22 hours and 185 million points were collected. Of those 22 million were for the exterior point clouds and 163 million for interior ones. This is due to the complexity of the interior of the monument. The laser scanner was placed in 12 different positions, 5 inside and 7 outside. For taking the images, 13 hours were approximately necessary, as the use of artificial lighting was imperative for the interior takings. 174 images were taken in total, 129 in the interior and the 45 in the exterior 
of the monument. The total capacity of these digital data is approximately $13.5 \mathrm{~GB}$, of which $3.3 \mathrm{~GB}$ occupy the laser scanner databases and 10.2 the digital images.

3.2.2 ZScan. ZScan is a system of $3 \mathrm{D}$ colored point cloud generation, through automated processing of digital images, which have been taken with a special system of stereoscopic triplets. The ZScan kit is composed by a DSLR camera (Nikon D90) with a fixed $24 \mathrm{~mm}$ lens, a slide bar of 900 (Figure 4 ) or $1600 \mathrm{~mm}$ length, on which the camera is sliding and is positioned in fixed points on the bar and, of course the ZScan software (http://www.menci.com/zscan/index.php?option=com content $\&$ task $=$ view\&id=10\&Itemid=28).

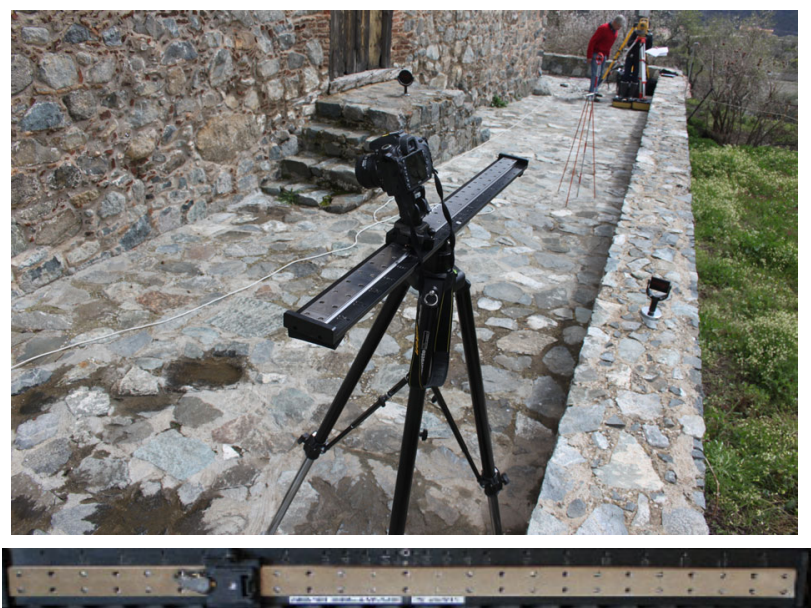

Figure 4: The typical setup of the ZScan and the slide bar

Image acquisition with ZScan is more or less similar to the classical terrestrial photogrammetric one, the only difference being that the user acquires triplets of images from the fixed positions on the slide bar. The factor that differentiates these two methods is the restriction of distance. With the ZScan system the operation range varies according to the length of the slide bar which will be used; from few centimeters, with the micro ZScan bar, up to $6 \mathrm{~m}$, with the slide bar of $900 \mathrm{~mm}$ length, or even 10 meters, with the slide bar of $1600 \mathrm{~mm}$ length. In order to avoid measuring a lot of GCP's, it is recommended that neighboring triplets should have model overlap greater than $20 \%$. When GCP's were measured, they were either pre-marked or detail points. The base varied from $500 \mathrm{~mm}$ to $900 \mathrm{~mm}$, depending on the camera to object distance. Some of the external imagery has been taken with the $1600 \mathrm{~mm}$ base with three synchronized Nikon D90 cameras. During photography, it is essential to record the base that each triplet is being recorded so that to import it in the software during processing.

Experience with the ZScan has shown that the closer the object of interest was situated, the more triplets were needed to cover it adequately, as it was the case in the interior with the confined space. On the other hand, for outside work, the longer slide bar was used. In total 211 triplets were acquired during three full days of field work and 9.5GB of disk space.

3.2.3 Horizontal and vertical sections. For the complete geometric documentation of the church one horizontal and six vertical sections were also determined, to serve as framework for the orthophotos (Figure 5).

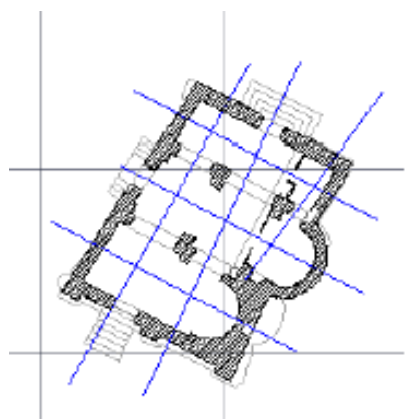

Figure 5: The footprints of the six vertical sections

The characteristic points of the sections were measured using a total station. For the interior the sections were measured using the TheolT software (http://www.theolt.com/web/) in combination with the Leica TPS 1200 total station and AutoCAD. This software actually intervenes between the total station and the CAD software by converting in real time the surveying measurements to coordinates while at the same time making available all CAD commands. The drawing is constructed in real time and in 3D (Figure 6).

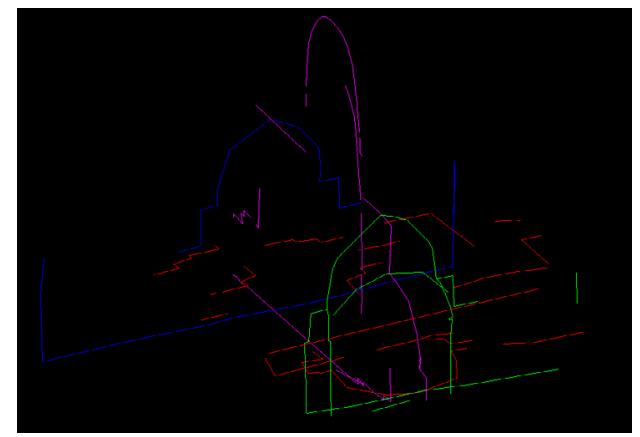

Figure 6: TheoLT real time 3D drawing

\section{DATA PROCESSING}

\subsection{TLS and Digital images}

The data processing stage includes processing of the survey measurements, aligning of the point clouds collected by the laser scanner and georeferencing them into the local reference system, as well as their conversion into surfaces. Calculating from point clouds the corresponding surfaces is a necessary process for the creation of the 3D model, which will be used for the stage of orthoimage production, but also for the rendering of the Digital Surface Model. The digital images taken were oriented using standard photogrammetric methods both for the creation of orthoimages, but also for texture mapping of the Digital Surface Model.

Data processing of the laser scanner point clouds was performed using Cyclone software which accompanies all Leica Laser Scanners. The interior and exterior point clouds were processed separately for better management of the information and because of the large amount of data. During the pre-processing phase all scans were cleaned from unnecessary noise, i.e. points belonging to objects not belonging to the monument itself, e.g. passing people, chairs, tables and other heavy things. Using the special retroreflective targets, the scans were registered in an arbitrary system. The maximum error at a target between two successive scans in the interior of the church was $4 \mathrm{~mm}$ and in the exterior $9 \mathrm{~mm}$. Both results were satisfactory and within the scale tolerances. After that, the measured dataset of the targets was imported to the software, as a new scan. The previously 
registered scans were then registered to this new one and thus referenced to the local coordinate system. This process was performed with accuracies of less than $12 \mathrm{~mm}$.

The next step was the mathematical creation of accurate surfaces from the set of the registered point clouds in order to create the $3 \mathrm{D}$ model of the church. The data processing of the point clouds was done using the Geomagic Studio ${ }^{\circledR}$ v.10 software. Once again, there was a separate process for the internal and external part of the church for the same reasons as before. The software provides a variety of automatic algorithms for point and triangle reduction. For the exterior, the points were reduced to 18 from 22 million and the triangles of the surface from $9 \mathrm{M}$ to $0.8 \mathrm{M}$ without significant loss of reliability. For the interior the decimation process reduced the points from $163 \mathrm{M}$ to $2 \mathrm{M}$ and the triangles to $0.8 \mathrm{M}$ again. During the meshing phases, holes in the final models caused by lack of information or noisy data were filled with the automatic hole filling tool. At the end of this process the two models were ready to be textured, and also to be used as Digital Surface Model at the stage of orthoimage production.

The next step was the orientation of the images that were taken and depicting the monument. This action was performed using Topcon's Image Master ${ }^{\circledR}$ software. A standard bundle adjustment algorithm is implemented by the software. The accuracies were well within the scale tolerances, i.e. less than $15 \mathrm{~mm}$ in $\mathrm{X}, \mathrm{Y}$ and $\mathrm{Z}$ both for the exterior and the interior images.

Orthoimage production followed using the oriented images and the Digital Surface Models imported into the Image Master ${ }^{\circledR}$ software in .dxf format. The final orthoimages were radiometrically corrected using standard image processing software for best optical results. Texture mapping of the models was also performed at this stage, while the model was divided in parts. Using a particular part of the model and the image that was best imaging it, rendering of the 3D model was done, while choosing the right rotation angles each time. When a texture map is created, at the program, the result is a rendered image of the textured model from a selected view and not a developed image of the textured surface of the model. This means that areas that are not visible in a view are poorly mapped (Valanis, Tapinaki, Georgopoulos, Ioannidis, 2009).
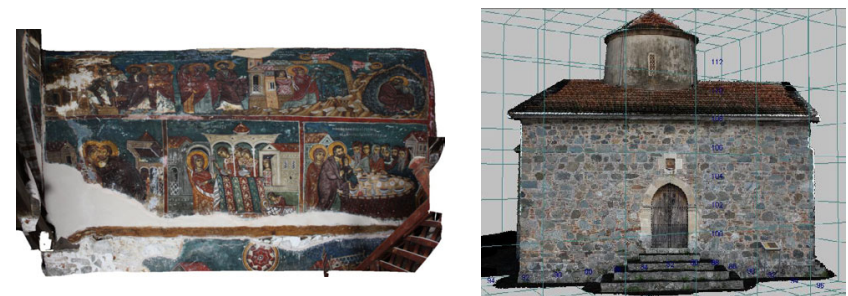

Figure 7: Results of the TLS and photogrammetric processing, orthoimage (left) and 3D rendered model (right)

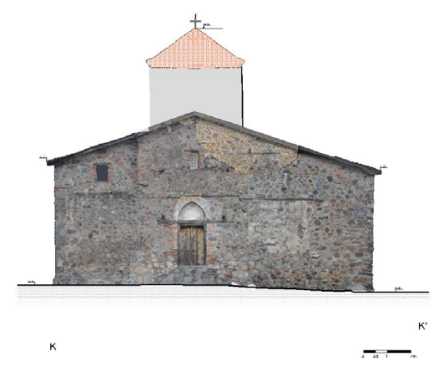

Figure 8: Orthophotomosaic of the western façade

\subsection{Zscan Triplets}

As already mentioned, Menci's Zscan is a medium to high cost trifocal photogrammetric system. It might be used with a single camera or three similar cameras synchronized for triggering. Cameras are calibrated by the company and can be positioned on a rigid bar mounted on a tripod. ZScan actually employs all Digital Photogrammetry principles, producing 3D point clouds via dense image matching procedures. However, photogrammetric processing in ZScan workflow differs from the standard one in the sense that the processing must be done in image triplets.

Triplets of images with a priori knowledge of relative positions are acquired, thus the $3 \mathrm{D}$ reconstruction of the scene is achieved via multi image matching software with a user friendly interface, but with no possibility for the user to intervene. The major advantage of the system is the ability to measure objects without any control, since the scale is obtained through the rigid bar and the known base. Relative orientation in being performed for every given triplet, since the positioning differs slightly each time the camera is positioned on the bar. If control points are available, they can be used for exterior orientation of the triplet provided that they can be measured in all images of the triplet. Additionally, if triplets have $20 \%$ overlap, the user can select "bundle" adjustment, which is an independent model adjustment.

The processing of the imagery up to surface creation is user friendly and straight forward with minimum options for the user. Image files are downloaded in the computer and with a semi automated way imported as triplets. For each triplet the base distance need to be typed. A list of coordinates is being used to import control points and the control points are manually measured in at least one image of each triplet. The software is using epipolar constrained image matching to locate the control in the rest images of the triplet and the user can correct it if necessary. After this initial process the user selects a number of triplets that he wishes to orient and runs bundle adjustment. Adjustment either finishes successfully or not, without any additional measure of correctness. Following that, all triplets are being processed for $3 \mathrm{D}$ point extraction and surface creation.

Both bundle adjustment and image matching are time consuming processes, the latter depending heavily on user options. The final product can be exported as color point cloud, or further processed using ZMap for orthophoto creation. ZMap allows the user to select appropriate projection plane and provides tools for $2.5 \mathrm{D}$ processing of the DEM prior to orthophoto creation.

\subsection{Products}

It was decided at the beginning that using both methodologies similar products would be produced, i.e. orthophotomosaics and a rendered 3D model, which would possibly lead to a video of virtual visualization. Consequently a number of drawings have been produced, most of them using both methodologies. These drawings, which include orthoimages fully document geometrically the monument. However, there are some problems, especially as far as the dome is concerned, because there was no possibility of hoisting the instrumentation at a suitable height. The surrounding area was not accessible by a vehicle. Some samples of these products are presented in Figures 8 \& 9 . 


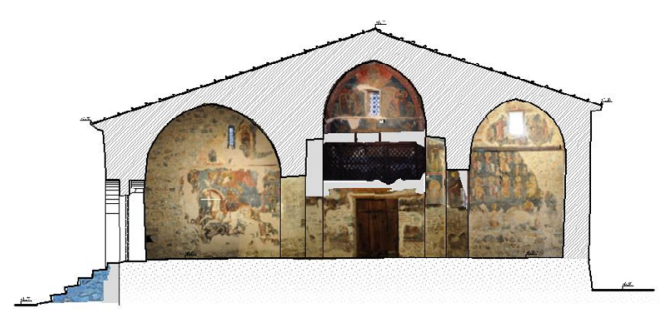

Figure 9: Vertical cross section facing east

In addition, the 3D model was constructed using the point clouds from the terrestrial laser scanner, as they were more complete. It was rendered using the Image Master ${ }^{\circledR}$ software and saved as a 3D Acrobat Reader ${ }^{\mathbb{B}}$ file (Figure 10).

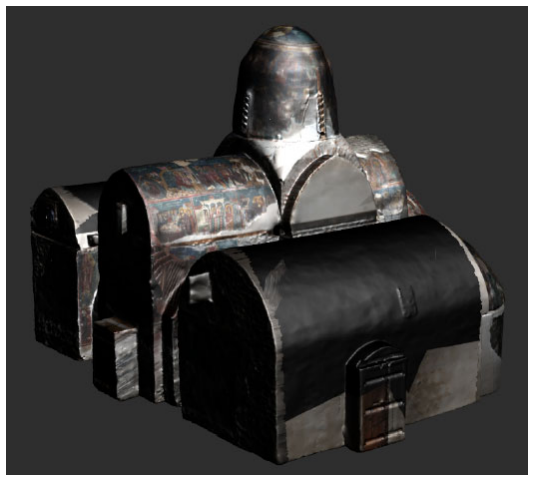

Figure 10: The 3D model of the interior of the church

\section{COMPARISON OF METHODOLOGIES}

Undoubtedly Zscan hardware is lighter, easier to transport and setup and all in all more operational than the particular terrestrial laser scanner. There are, however, terrestrial laser scanners already in the market, which are not of that size. The laser scanner is heavy and huge comparing to ZScan, as well as approximately four to five times more expensive. Moreover Zscan appears to be more effective in areas where access is limited. Moreover the transportation and the installation of the laptop accompanying the laser scanner were rather time consuming actions and often distracting.

Data acquisition differs a lot between the two techniques. TLS was faster in the inside, where the Zscan system, due to the confined space and despite of the use of $24 \mathrm{~mm}$ lens had to compensate with many photo triplets for full coverage. Outside of the church, the situation is reversed. In any case the TLS process had to be followed with an image acquisition session for texturing, which slowed down the overall process.

The total time of raw data collection in the case of ZScan was $55 \%$ less than that of the laser scanner. On the other hand laser scanner produces the $3 \mathrm{D}$ point cloud in real time, contrary to Zscan, which needs a time consuming procedure in order to create a point cloud. Nevertheless, ZScan creates a 3D point cloud complete with texturing information, while laser scanner does not. A complete time comparison is presented in Table 1.

Undoubtedly, as it was mentioned before, laser scanner predominates in controlling the acquired data in situ, as the user can examine the point cloud in real time. Therefore, human error factor reduces in this case, in contrast to ZScan, where the user is very likely to miss out part of the object. Moreover, in the case of the laser scanner the cloud density is determined at the time of data acquisition and can only be decreased later.

As far as range is concerned, it is one of ZScan's biggest disadvantages since it does not allow the user to capture surfaces which are more than $10 \mathrm{~m}$ away even with the longer available slide bar. In contrast, the range of this specific type of laser scanner $(\mathrm{ToF})$ reaches $200 \mathrm{~m}$.

The volume of data collection is huge in the case of the laser scanner, because mainly the increased density applied in the case of the dome interior. The files which are generated were difficult to manage and data ought to be processed separately, which would be done anyway. On the other hand, the size and the organization of files in the case of the ZScan are quite easier provided that care has been taken during fieldwork to note down all particular details. Furthermore, the number of the control points necessary to georeference the triplets was less in the case of the Zscan compared to the total number of GCP's necessary for the orientation of the digital images. On the other hand, 13 scans were necessary to cover the inside and outside of the monument with the laser scanner, while with the Zscan 95 different setups were needed. This leads to more tedious fieldwork and to eventual errors in point cloud registrations later.

\begin{tabular}{|c|c|c|}
\cline { 2 - 3 } \multicolumn{1}{c|}{} & Z-scan & TLS+DSLR \\
\hline $\begin{array}{c}\text { Survey } \\
\text { Measurements } \\
\text { (common) }\end{array}$ & 110 & 110 \\
\hline Fieldwork & 27 & 35 \\
\hline 3D point cloud & 500 & 440 \\
\hline Orthoimages & 300 & 360 \\
\hline $\begin{array}{c}\text { Radiometric } \\
\text { corrections }\end{array}$ & 80 & 35 \\
\hline Texture mapping & - & 33 \\
\hline $\begin{array}{c}\text { Final drawings } \\
\text { (common) }\end{array}$ & 120 & 120 \\
\hline \hline Total time (hrs) & 1137 & 1133 \\
\hline
\end{tabular}

Table 1: Comparison of methodologies (hours)

The production of orthoimages in the ZMap software is much quicker than with the conventional method. It should, however, be noted that the possibility for corrections to the Digital Surface Models is limited in the case of Zscan. Its main advantage is the unified manipulation of the surface and the imagery, which provides high quality $3 \mathrm{D}$ photorealistic models and excellent orthophotos. Since calibrated cameras are being used, there is no remaining effect of radial distortion that cannot be modeled with DLT (in comparison with laser data and external camera). On the other hand its use in confined spaces is awkward, as the number of triplets is increased rapidly.

As far as total time and consequently total cost are concerned, the two methodologies have been evaluated with the survey of the specific monument in mind. Surveying measurements were common, as the basic coordinate reference system should be common in order for the results and their comparison to be objective. In Table 1 the results of the time statistics for both methods are presented. Finally, it should be noted that both techniques make use of costly equipment and software. If cost estimation was attempted, the ZScan method would prove only by $5 \%$ cheaper. 


\section{CONCLUDING REMARKS}

The geometric documentation of monuments is a challenging and complex task and both techniques managed to support it adequately. They proved to be complementary to each other as no method appears to have a clear advantage over the other. Of the two methods ZScan has the advantage of being an automated method that does not require the user of having a photogrammetric knowledge whereas the disadvantage is the incompatibility with other software. Both techniques as for their final accuracy deliver satisfactory results within the scale tolerances. Each technique has merits in different fields, e.g. if a low density model is required, Zscan is ideal as it may provide it very fast and does not require special knowledge from the user.

\section{ACKNOWLEDGEMENTS}

The authors wish to acknowledge the support of the official air carrier of our on-going project Cyprus Airways for the transfer of the equipment from Greece, as well as the help of the Church of Cyprus, the Archbishop of Limassol and that of the Department of Antiquities of Cyprus who granted their kind permission for the works in the Church of the Holy Cross in Pelendri. In addition the help and support of the local superintendent of the church Mr. Tsangaris and of course $\mathrm{Mr}$ Andreas and his wife Anastasia is also acknowledged.

\section{REFERENCES}

\section{References from Journals:}

Georgopoulos, A., Ioannidis, Ch., 2007. Innovative Techniques for the Acquisition and Processing of Multisource Data for the Geometric Documentation of Monuments. International Journal of Architectural Computing Volume 5, Number 2, 2007, pp. 179-197.

Georgopoulos, A., Ioannidis, Ch., Crysostomou, Ch., Ioakim, S., Shieittanis, N., Ioannides, M., 2009. Contemporary digital methods for the Geometric Documentation of Churches in Cyprus. International Journal of Architectural Computing, Volume 07, Number 01, 2009, pp. 21-37.

\section{References from Books:}

Hadjichristodoulou, Ch., 2005. "The Church of the Holy Cross", Nicosia, pp.127, (in Greek).

U.N.E.S.C.O., 1972. Photogrammetry applied to the survey of Historic Monuments, of Sites and to Archaeology. UNESCO editions.

Zarras N., 2010. The Church of the Holy Cross in Pelendri, Holy Archbishopric of Limassol, pp. 85 (in Greek).

\section{References from Other Literature:}

Agapiou, A., Georgopoulos, A., Ioannidis, Ch., Doulamis, N., Ioannides, M., 2008a. Three dimensional reconstruction for Cultural Heritage visualization. Application to the Byzantine Churches of Cyprus. Proceedings of CAA Conference on the Road to reconstructing the past, Budapest April 2008.

Agapiou, A., Georgopoulos, A., Ioannides, M., Ioannidis, Ch., 2008b. A Web Based GIS for the Byzantine Churches of Cyprus. VSMM 2008 - Conference on Virtual Systems and MultiMedia
Dedicated to Digital Heritage, 20-25 October 2008, Project Paper Volume p. 148-151.

Agapiou, A., Georgopoulos, A., Ioannidis, Ch., Ioannides, M., 2010. A Digital Atlas for the Byzantine and Post Byzantine Churches of Troodos region (central Cyprus). Proceedings of the $38^{\text {th }}$ Conference on Computer Applications and Quantitative Methods in Archaeology Granada, Spain, April 2010.

Crysostomou, Ch., Ioakim, S., Shieittanis, N., Georgopoulos, A., Ioannidis, Ch. 2008. Contemporary digital methods for the Geometric Documentation of Churches in Cyprus. VSMM 2008 - Conference on Virtual Systems and MultiMedia Dedicated to Digital Heritage, 20-25 October 2008, Project Paper Volume p.24-28.

Sofocleous, E., Georgopoulos, A., Ioannides, M., Ioannidis, Ch., 2006. The Geometric Documentation of the Asinou Church in Cyprus. VAST 2006, Lefkosia Cyprus, Oct-Nov. 2006. The e-volution of Information Communication Technology in Cultural Heritage (eds. M. Ioannides et al.), p. 138-144 ISBN10: 9638046759 .

Stathopoulou E.K., 2011. Three dimensional models of Complex Architectural Surfaces. Diploma Thesis, Lab. of Photogrammetry, NTUA (in Greek).

Valanis, A., Tapinaki, S., Georgopoulos, A., Ioannidis, C., 2009. High Resolution Textured Models for Engineering Applications. 22nd CIPA Symposium, Kyoto, Japan.

\section{References from websites:}

http://www.theolt.com/web/

http://www.menci.com/zscan/index.php?option=com_content\&t ask=view\&id=10\&Itemid=28. Menci Software, 2011. "Zscan 3d scanning without laser" Last accessed: 10-5-2011

http://www.rp-photonics.com/z_scan_measurements.html, RP photonics, 2011. "ZScan Measurements". Last accessed: 20-92011 